\title{
Publisher Correction: A PRDX1 mutant allele causes a MMACHC secondary epimutation in $c b / C$ patients
}

Jean-Louis Guéant ${ }^{1}$, Céline Chéry ${ }^{1}$, Abderrahim Oussalah (10 1, Javad Nadaf ${ }^{2}$, David Coelho (1) 1, Thomas Josse ${ }^{1}$, Justine Flayac ${ }^{1}$, Aurélie Robert ${ }^{1}$, Isabelle Koscinski ${ }^{1}$, Isabelle Gastin ${ }^{1}$, Pierre Filhine-Tresarrieu', Mihaela Pupavac ${ }^{2}$, Alison Brebner ${ }^{2}$, David Watkins ${ }^{2}$, Tomi Pastinen ${ }^{2}$, Alexandre Montpetit ${ }^{2}$, Fadi Hariri ${ }^{2}$, David Tregouët ${ }^{3}$, Benjamin A Raby ${ }^{4}$, Wendy K. Chung ${ }^{5}$, Pierre-Emmanuel Morange ${ }^{6}$, D. Sean Froese ${ }^{7}$, Matthias R. Baumgartner ${ }^{7}$, Jean-François Benoist ${ }^{8}$, Can Ficicioglu9 ${ }^{9}$, Virginie Marchand ${ }^{10}$, Yuri Motorin ${ }^{10}$, Chrystèle Bonnemains ${ }^{1}$, François Feillet', Jacek Majewski id ${ }^{2} \&$ David S. Rosenblatt ${ }^{2}$

Correction to: Nature Communications https://doi.org/10.1038/s41467-017-02306-5, published online 4 January 2018

The original version of this Article contained an error in the title, which was incorrectly given as "APRDX1 mutant allele causes a $M M A C H C$ secondary epimutation in cblC patients". This has now been corrected in both the PDF and HTML versions of the Article to read "A PRDX1 mutant allele causes a MMACHC secondary epimutation in cblC patients".

Published online: 02 February 2018

reproduction in any medium or format, as long as you give appropriate credit to the original author(s) and the source, provide a link to the Creative Commons license, and indicate if changes were made. The images or other third party material in this article are included in the article's Creative Commons license, unless indicated otherwise in a credit line to the material. If material is not included in the article's Creative Commons license and your intended use is not permitted by statutory regulation or exceeds the permitted use, you will need to obtain permission directly from the copyright holder. To view a copy of this license, visit http://creativecommons.org/licenses/by/4.0/.

(c) The Author(s) 2018

\footnotetext{
${ }^{1}$ INSERM, UMR_S954 Nutrition-Genetics-Environmental Risk Exposure and Reference Centre of Inborn Metabolism Diseases, University of Lorraine and University Hospital Centre of Nancy (CHRU Nancy), 54505 Nancy, France. ${ }^{2}$ Department of Human Genetics, McGill University and Research Institute McGill University Health Centre, H4A 3J1 Montreal, Quebec, Canada. ${ }^{3}$ Sorbonne Universités, UPMC University Paris 06, Institut National pour la Santé et la Recherche Médicale (INSERM), ICAN Institute for Cardiometabolism and Nutrition, Unité Mixte de Recherche en Santé (UMR_S) 1166, Team Genomics \& Pathophysiology of Cardiovascular Diseases, 75013 Paris, France. ${ }^{4}$ Channing Division of Network Medicine, Department of Medicine, Brigham and Women's Hospital, Harvard Medical School, 02115 Boston, MA, United States of America. ${ }^{5}$ Departments of Pediatrics and Medicine, Columbia University, 10032 New York, NY, United States of America. ${ }^{6}$ INSERM, UMR_S1062, Nutrition Obesity and Risk of Thrombosis, Aix-Marseille University, 13005 Marseille, France. ${ }^{7}$ Division of Metabolism and Children's Research Centre (CRC), University Children's Hospital, CH-8032 Zürich, Switzerland. ${ }^{8}$ Service de Biochimie Hormonologie, Hôpital Robert Debré, 75019 Paris, France. ${ }^{9}$ Children's Hospital of Philadelphia, Perelman School of Medicine at the University of Pennsylvania, 19104 Philadelphia, PA, United States of America. ${ }^{10}$ Laboratoire Ingénierie Moléculaire et Physiopathologie Articulaire (IMoPA), UMR7365 CNRS - Université, de Lorraine and FR3209 CNRS- Université de Lorraine, 54505 Nancy, France Correspondence and requests for materials should be addressed to J.-L.Géa. (email: jean-louis.gueant@univ-lorraine.fr)
} 